\title{
Litoral Libras: plataforma virtual da Língua Brasileira de Sinais com foco nas variações linguísticas do litoral norte gaúcho para a promoção da acessibilidade entre surdos e ouvintes
}

\author{
Litoral Libras: virtual platform of the Brazilian Sign Language with a \\ focus on linguistic variations on the north coast of Rio Grande do Sul to \\ promote accessibility among deaf and hearing people
}

\author{
Aline Dubal Machado ${ }^{1}$ \\ Ingrid Gonçalves Caseira ${ }^{2}$ \\ Ana Clara Jardim da Silva ${ }^{3}$
}

\begin{abstract}
Resumo
A Língua Brasileira de Sinais (Libras) configura-se como uma língua legítima e genuína como as demais, diferindo apenas por sua modalidade gestual-visual (GESSER, 2010). Assim, ela não apresenta unidade e sofre variações. No litoral norte gaúcho, essas diferenciações são também perceptíveis e marcantes. Observou-se que a comunidade surda local apresentava uma crescente demanda por materiais de pesquisa e estudos da Libras específicos à região. Desta forma, este trabalho objetivou o desenvolvimento de uma plataforma virtual de aprendizagem, contendo um glossário com sinais utilizados na região e que levam em consideração as variações linguísticas locais, além de materiais teóricos e informativos acerca desta língua e comunidade. A presente pesquisa, de caráter exploratório, dividiu-se em duas etapas metodológicas: pesquisa bibliográfica e estudo de caso. Nesse último, foi-se a campo com a finalidade de reunir-se com cinco sujeitos surdos de diferentes cidades da região, a fim de recolher o registro da forma como cada um realizava sinais presentes em quatro listas semânticas. Posteriormente, realizou-se a análise quanto às variantes linguísticas das listas, buscando identificar as variações presentes na sinalização do território em relação ao restante do estado e país, além de averiguar-se quais os sinais mais utilizados no litoral norte gaúcho para tais palavras analisadas, objetivando-se compor o glossário disponibilizado na plataforma. Concluídas as análises, foi possível constatar a presença de variações linguísticas em todas as quatro listas semânticas, bem como nos três níveis geográficos investigados (regional, estadual e nacional). Reafirmou-se, assim, a necessidade de materiais produzidos para a região, como a plataforma Litoral Libras, auxiliando a promoção da acessibilidade comunicativa entre surdos e ouvintes.
\end{abstract}

Palavras-chave: Acessibilidade comunicativa. Língua Brasileira de Sinais. Variação linguística.

Abstract

The Brazilian Sign Language (Libras) is configured as a legitimate and genuine language like the others, differing only by its gestural-visual modality (GESSER, 2010). Thus, it has no unity and suffers variations. On the north coast of Rio Grande do Sul, these differences are also noticeable and striking. It was observed that the local deaf community had a growing demand for Libras research materials and studies specific to the region. This way, the objective of this work was to develop a virtual learning platform, containing a glossary with signs used in the region and which take into account local linguistic variations, in addition to theoretical and informative materials about this language and community. This exploratory research was divided into two methodological steps: bibliographic research and case study. In the latter, a meeting was organized with five deaf subjects from different cities in the region, in order to collect the record of how each performed signs present in four semantic lists. After, the analysis regarding the linguistic variants of the lists was carried out, seeking to identify the variations present

\footnotetext{
${ }^{1}$ Mestra em Distúrbios da Comunicação Humana. Instituto Federal de Educação, Ciência e Tecnologia do Rio Grande do Sul - Campus Osório, Osório, Rio Grande do Sul, Brasil. Orcid: https://orcid.org/0000-0002-6604-7149. E-mail: aline.dubal@osorio.ifrs.edu.br

2 Mestra em Letras. Instituto Federal de Educação, Ciência e Tecnologia do Rio Grande do Sul - Campus Osório, Osório, Rio Grande do Sul, Brasil. Orcid: https://orcid.org/0000-0002-7371-2506 E-mail: ingrid.caseira@osorio.ifrs.edu.br

3 Técnica em Administração. Instituto Federal de Educação, Ciência e Tecnologia do Rio Grande do Sul - Campus Osório, Osório, Rio Grande do Sul, Brasil. Orcid: https://orcid.org/0000-0002-3851-6809 E-mail: anaclarajardim.acj3@gmail.com
} 
in the signs of the territory compared to the rest of the state and country, in addition to investigate which signs are most used in the north coast of Rio Grande do Sul for such analyzed words, aiming to compose the glossary available on the platform. After the analysis, it was possible to verify the presence of linguistic variations in all four semantic lists, as well as in the three geographic levels investigated (regional, state and national). Thus, the need for materials produced for the region was reaffirmed, such as the Litoral Libras platform, helping to promote communicative accessibility between deaf and listeners.

Keywords: Communicative accessibility. Brazilian Sign Language. Linguistic variations.

\section{Introdução}

A presente pesquisa procurou estudar as variações linguísticas da Língua Brasileira de Sinais (Libras) na comunidade surda do litoral norte gaúcho, tendo em vista que foi observado que os indivíduos da localidade realizavam sinais diferentes para uma mesma palavra e que esses sinais realizados por eles diferiam ainda mais quando comparados ao restante do Rio Grande do Sul e do Brasil. Compreendese que essa constatação tem relação com o fato de o Rio Grande do Sul ser um estado com grande extensão territorial e contribuição cultural de diversos povos, o que afeta também a língua. Atrelando essa condição ao fato de que ainda não havia sido produzido nenhum dicionário bilíngue direcionado à região do litoral norte gaúcho, teve-se a ideia do desenvolvimento desta pesquisa com vista a atender a essa demanda.

Assim, almejou-se suprir a escassez de um recurso que amparasse o aprendizado e difusão da língua de sinais no litoral, pois é possível dizer que a maneira mais efetiva para a inclusão do sujeito surdo em nossa sociedade seja eliminando as barreiras de comunicação entre eles e ouvintes.

O estudo buscou utilizar-se das novas tecnologias, neste caso, a plataforma virtual Litoral Libras, como ferramenta substancial no aprendizado de Língua Brasileira de Sinais pela comunidade do litoral norte gaúcho. Para tanto, levou-se em consideração as variações linguísticas presentes na Libras utilizada nesse território, pois entende-se sua importância para o fortalecimento identitário e cultural da comunidade surda local.

Este trabalho divide-se em cinco seções. Primeiramente, o referencial teórico e entendimentos que embasam o desenvolvimento da pesquisa, na sequência, o percurso metodológico, os resultados e discussões e, por fim, as considerações finais.

\subsection{Justificativa}

Um dos grandes mitos enraizado em nossa sociedade é o de que a Libras é universal. Esse pensamento surge da ideia de que as línguas de sinais foram criadas como um código e disseminadas 
pelo mundo. Essa ideia rompe com o conceito da pluralidade cultural humana, segundo o qual cada ser possui um jeito único de enxergar o mundo e de se relacionar com ele. Isso se reflete também na língua.

A língua dos surdos não pode ser considerada universal, dado que não funciona como um "decalque" ou "rótulo" que possa ser colocado e utilizado por todos os surdos de todas as sociedades de maneira uniforme e sem influências de uso (GESSER, 2009, p. 12).

Assim, a Libras, como qualquer outra língua, sofre variações ao longo dos territórios, estando em constante mudança. Veja, por exemplo, como é encontrado o sinal da palavra "colchão" em um dicionário produzido em Porto Alegre - RS e, após, em um produzido em São Paulo - SP;

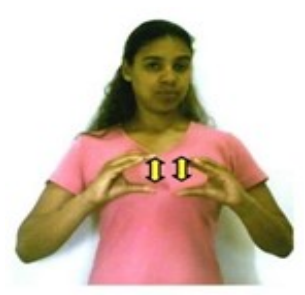

Figura 1. Sinal em Libras da palavra colchão Fonte: Minidicionário de Libras da FADERS

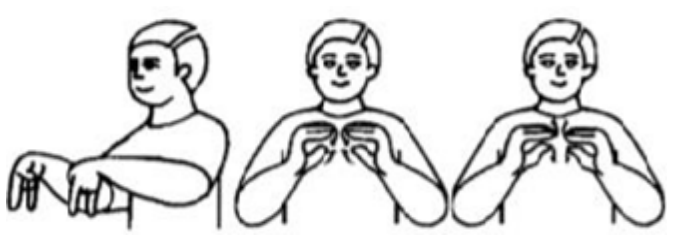

Figura 1. Sinal em Libras da palavra colchão

Fonte: Dicionário llustrado Enciclopédico Trilíngue (DIET) de Língua de Sinais Brasileira

Depreende-se, assim, a necessidade de que os materiais didáticos desenvolvidos reconheçam as variações existentes de comunidade para comunidade e que também sejam pensados materiais com um olhar dedicado especialmente a uma determinada comunidade, entendendo as variações como algo pertinente à formação de identidade cultural dos sujeitos surdos. De um lado, então, contribui-se para que não haja prejuízos no momento da aprendizagem e posterior comunicação e, de outro, o próprio levantamento dessas variações mostra o caráter vivo e dinâmico da Libras, típico de toda e qualquer língua enquanto organismo vivo.

Além disso, por se tratar de um campo tão vasto e recente, tendo em vista que a Língua Brasileira de Sinais foi oficializada somente em 2002 com a Lei 10.436: "Art. $1^{\circ}$ É reconhecida como meio legal de comunicação e expressão a Língua Brasileira de Sinais - Libras e outros recursos de expressão a ela associados." (BRASIL, 2002); há poucas investigações neste campo, enfatizando-se a necessidade de estudos que venham suprir essa carência. 
1.2 Objetivos

O objetivo geral deste trabalho é a promoção da acessibilidade comunicativa no litoral norte gaúcho através do desenvolvimento de uma plataforma virtual com foco nas variações linguísticas dessa região, contendo um glossário de sinais e materiais teóricos acerca desta língua, a fim de amparar o aprendizado e difundir a língua de sinais em uso no litoral norte gaúcho.

\section{Referencial Teórico}

\subsection{Sociolinguística Variacionista}

A ciência que estuda a linguagem e as línguas naturais é a linguística. Por sua vez, a área da linguística que interessa especialmente para a realização do presente estudo é a Sociolinguística, mais especificamente a Sociolinguística Variacionista ou Laboviana, em razão de se preocupar principalmente com as variações e a mudança na língua. Ela é responsável por estudar a relação existente entre a língua que falamos e a sociedade em que vivemos, como o próprio nome já revela (COELHO, 2015, p. 12). Quando pensamos nessa associação, devemos ter em mente que o grupo social em que estamos inseridos influencia diretamente no modo como falamos, e o modo como falamos pode revelar facilmente ao ouvinte o grupo social ao qual pertencemos. Isto porque, mesmo que todos falemos o português e nos entendamos perfeitamente ao longo de todo o território brasileiro, cada comunidade, ou cada indivíduo, se utiliza da língua de uma forma diferente.

As diferenciações no modo como cada sujeito utiliza a língua são denominadas variações linguísticas. Para Coelho (2015, p.16), "a variação linguística é o processo pelo qual duas formas podem ocorrer no mesmo contexto com o mesmo valor referencial/representacional, isto é, com o mesmo significado". Logo, a variante linguística é uma característica que trata do uso de uma língua, carrega os "sotaques" que são manifestados a partir das relações sociais, sendo que os sujeitos, ao falarem, são identificados segundo a região e cultura às quais pertencem. No caso, a língua de sinais (LS) também pode ser reconhecida pela região à qual faz parte, pois tem em suas características a variação linguística, a qual the assegura ser uma língua natural e genuína (KARNOPP, 2009).

Dessa forma, pode-se compreender que a incidência quanto à variante linguística pode ser relacionada diretamente com a questão geográfica. Corroborando com a ideia, apresentam-se as considerações de Santos, Pereira e Lebedeff (2019, p.185), 
a variação sociolinguística leva em consideração o fato de diferentes variantes linguísticas poderem estar relacionadas com fatores sociais, incluindo idade, classe econômica, gênero, etnia, região e orientação sexual. Por exemplo, pessoas mais velhas podem fazer uso mais frequente de uma determinada variante em comparação com pessoas mais jovens; mulheres podem usar certa variante em menor frequência que homens; outra determinada variante pode ser mais usada por pessoas de classe operária do que pessoas da classe média.

Logo, a Libras apresenta significativas variações linguísticas nas diferentes comunidades surdas presentes nos distintos territórios nacionais, sendo possível identificar que esses grupos se organizam e se atualizam conforme o uso dos sinais que sofrem influência das características de seus usuários, tais como: idade, escolaridade, maior ou menor contato com a comunidade surda, sexo, classe social, personalidade e estado emocional. Conforme nos respalda Karnopp:

ao estudarmos as línguas de sinais, estamos tratando também das relações entre linguagem e sociedade. A linguística, ao estudar qualquer comunidade que usa uma língua, constata, de imediato, a existência de diversidade ou de variação, ou seja, a comunidade linguística (no caso aqui investigado, a comunidade de surdos) se caracteriza pelo emprego de diferentes modos de usar a língua de sinais. A essas diferentes maneiras de fazer sinais, utiliza-se a denominação de "variedades linguísticas" (2009, p. 06 - 07).

Desse modo, as variações linguísticas fazem parte das línguas em uso, sendo que os sujeitos que utilizam uma determinada língua carregam consigo suas características como uma marca de determinada região ou grupo sociocultural, reconhecidas através dessas variantes.

Para Santos, Pereira e Lebedeff (2019, p. 185), "no Brasil foram encontradas poucas pesquisas sobre as variações linguísticas na Libras". Assim, sendo poucas as pesquisas e estudos nesta área voltados a Libras e, até então, nenhuma específica ao litoral norte gaúcho, a pesquisa traz necessidade e ineditismo ao estudo.

\subsection{Língua Brasileira de Sinais: identidade, cultura e comunidade}

A sociedade atual ainda possui preconcepções equivocadas em relação à Língua Brasileira de Sinais (Libras), portanto, é necessário, antes de tudo, romper com o senso comum e compreender que a Libras, ao contrário da crença de muitos, é uma língua que não está associada a mímicas, pantomimas e gestos banais. As línguas de sinais, bem como as línguas orais, são naturais, genuínas e legítimas, diferindo das demais apenas pela sua modalidade gestual e visual. São um canal comunicativo efetivo e complexo, capaz de expressar ideias e conceitos abstratos (BRASIL, 2002).

Logo, as línguas de sinais são línguas que se configuram de modo diferente, isto é, possuem a modalidade de uma língua gestual-visual, porque são produzidas por sinais manuais e compreendidas 
pela percepção visual. Dessa forma, por ser de fácil percepção e compreensão para a comunidade surda por sua hábil capacidade visual e gestual, a língua de sinais é considerada por essa comunidade como sua língua natural, a língua que os constitui e os representa. A língua de sinais é natural, como toda e qualquer língua oral, porque incorpora e transmite a cultura, a arte, a poesia e a luta do povo surdo.

No Brasil, a Língua Brasileira de Sinais (Libras) foi oficializada segunda língua oficial do país, marcando uma grande conquista na luta dos movimentos sociais da comunidade surda. A oficialização se deu através da Lei 10.436 de abril de 2002, que dispõe sobre a Libras - Língua Brasileira de Sinais e dá outras providências:

Art. $1^{\circ}$ É reconhecida como meio legal de comunicação e expressão a Língua Brasileira de Sinais - Libras e outros recursos de expressão a ela associados.

Parágrafo único. Entende-se como Língua Brasileira de Sinais - Libras a forma de comunicação e expressão, em que o sistema linguístico de natureza visual-motora, com estrutura gramatical própria, constitui um sistema linguístico de transmissão de ideias e fatos, oriundos de comunidades de pessoas surdas do Brasil. (BRASIL, 2002).

O que confere a ela status de língua é o fato de possuir uma gramática própria e estrutura composta por todos os níveis: fonológico, morfológico, sintático e semântico. Ainda, apresenta outros aspectos linguísticos, como flexibilidade, descontinuidade e arbitrariedade (GESSER, 2010).

A língua é uma das principais instituições que caracteriza e compõe a cultura de determinado grupo de indivíduos. É através dela que os sujeitos constroem sua identidade e manifestam a cultura da qual fazem parte, assim também é com os surdos. A língua como constituinte de uma cultura não é uniforme e universal, ela varia de acordo com alguns critérios já citados anteriormente. Dessa forma,

dizer que todos os brasileiros falam o mesmo português é uma inverdade, na mesma proporção que é inverdade dizer que todos os surdos usam a mesma Libras. Afirmar essa unidade é negar a variedade de línguas, quando de fato, nenhuma língua é uniforme, homogênea. (GESSER, 2009, p. 39)

A Libras é a língua constituidora da comunidade surda, ela provê o desenvolvimento e o aprendizado desse grupo linguístico e cultural específico. De acordo com Monteiro, Silva e Ratner (2013), a surdez é uma condição que causa ao indivíduo incapacidade de identificar alguns sons. Ela pode ser classificada quanto aos tipos: perda auditiva condutiva, perda auditiva sensorial e também quanto às causas: congênita (o sujeito já nasce com a condição) ou adquirida (como consequência de alguma complicação ou doença). Segundo esses autores, a única barreira que os deficientes auditivos têm de enfrentar é a da comunicação, o que impede que esses sujeitos interajam e sejam incluídos, de fato, em suas famílias (pensando em pais ouvintes e não sinalizadores, como ocorre na maioria dos casos) e na sociedade (que possui uma língua materna falada e não busca o aprendizado da língua de sinais). 
Para Lane (2012), até a década de 1970, a surdez foi vista como uma deficiência e uma anomalia. Logo, os sujeitos surdos foram encarados como menos capazes intelectual e socialmente. Assim, por muito tempo, se fortaleceu o incentivo a implantes cocleares e uso de próteses auditivas. Além, é claro, da introdução da língua falada de forma "forçada" às crianças com perda auditiva - prática conhecida como oralismo.

Segundo Machado (2002), o oralismo baseia-se na evolução linguística da criança ouvinte, faz uso do treino da fala, articulação das palavras, leitura orofacial e objetiva integrar o surdo ao mundo dos ouvintes, moldando-o a uma única identidade: a de ouvinte. Anteriormente, esse modelo foi muito utilizado como única forma de conduzir a formação e o desenvolvimento dos sujeitos surdos, mas, atualmente, isso mudou.

De acordo com Bisol e Sperb (2010, p. 08),

Na década de 1970, ganhou força o modelo cultural de surdez, também conhecido em nosso meio como modelo socioantropológico. Foi construída uma área de estudos chamada Deaf Studies (Estudos Surdos), que se dedica a pensar os conceitos de identidade, cultura, poder e linguagem.

Nessa época, a surdez passa a ter um novo olhar, ou seja, passa a ser vista por um viés cultural. Portanto, há uma nova compreensão da surdez como uma diferença, e não mais como deficiência. Essa ideia é aceita até os dias de hoje, sobretudo pelas comunidades surdas.

Para corroborar com o novo cenário, tem-se o Decreto 5.626, de 2005, o qual, no Art. $2^{0}$ considera-se pessoa surda aquela que, por ter perda auditiva, compreende e interage com o mundo por meio de experiências visuais, manifestando sua cultura principalmente pelo uso da Língua Brasileira de Sinais - Libras.

Desta forma, as línguas de sinais conferem, às pessoas surdas, sua identidade própria. E essa seria adquirida apenas com o contato com outro surdo (SANTANA; BERGAMO, 2005). Neste cenário, compreende-se que, para o sujeito surdo, a melhor proposta é o bilinguismo, no qual a língua natural, a Libras, surge como produto e fator determinante no desenvolvimento e aprendizado dos sujeitos surdos.

Logo, considera-se de extrema importância a relação surdo-surdo, pois fomenta a constituição da identidade, legitima o uso e a disseminação da língua de sinais, bem como fortalece as relações da comunidade surda. 
2.3 Plataforma virtual de aprendizagem

O século XX foi um período de grande desenvolvimento e avanço das novas tecnologias, sobretudo o advento da internet que muda, com o tempo, drasticamente o modo de vida das pessoas, que têm de se adaptar ao novo mundo globalizado e informatizado (CAVALCANTE; SILVA, 2011). Assim, "a grande repercussão emergida da evolução das novas tecnologias constitui-se certamente nos novos espaços e nas novas formas de relacionamento. Sejam pessoais, de negócios, de educação ou lazer" (COMASSETO, 2006, p. 21).

Neste contexto de surgimento de novos espaços, apresentam-se os espaços virtuais de aprendizagem, que têm ganhado cada vez mais adeptos, principalmente com a consolidação da EaD Educação a Distância (GABARDO; QUEVEDO; ULBRICHT, 2010). Há, a partir de então, uma busca por transformar este espaço virtual, não pensado inicialmente com um objetivo educacional, em um espaço capaz de abrigar os processos de ensino e aprendizagem. Assim, ainda de acordo com os autores supracitados, estão disponíveis diversas plataformas pelas quais este processo pode se desenvolver, e "nelas, estão embutidos contornos tecnológicos e pedagógicos para o desenvolvimento de metodologias educacionais, utilizando canais de interação Web aptos a oferecer suporte para atividades educacionais de forma virtual" (GABARDO; QUEVEDO; ULBRICHT, 2010, p. 67).

Um recurso muito utilizado como plataforma virtual de aprendizagem são os Websites, os quais, segundo Carvalho, Simões e Silva (2004, p. 21), são "uma coleção estruturada de páginas Web, representando uma entidade (empresa, organização, grupo) ou alguém (uma pessoa)". Ainda, para os mesmos autores, a estrutura é constituída por páginas, ficheiros e hiperlinks, podendo esses conduzirem a outras abas do site ou a outras páginas da Web.

Com o mundo globalizado e cada vez mais conectado, entende-se que trazer os processos de ensino e aprendizagem para o espaço virtual significa democratizar o acesso ao conhecimento, sobretudo quando esses espaços referem-se a plataformas educativas, gratuitas e inclusivas, como 0 caso da plataforma virtual Litoral Libras, desenvolvida neste estudo.

Ademais, já se sabe que a internet é um espaço de grande interação por parte dos sujeitos surdos, que participam de grupos nas redes sociais com outros surdos de diversos lugares do país. Para Quadros (2017, p. 23), "no Brasil, as associações de surdos sempre mantiveram intercâmbio por meio de redes, possibilitando contatos entre surdos do país inteiro. (...). Atualmente, essas redes estão potencializadas por meio do uso de celulares e internet." Logo, considera-se que a conexão entre os 
sujeitos surdos via ferramentas virtuais, com intuito educacional ou de assegurar a Libras e potencializar a interação, como mais um caminho necessário e viável nos dias de hoje.

\section{Metodologia}

O presente estudo, quanto ao seu objetivo, se encaixa no tipo de pesquisa exploratória e, quanto aos seus procedimentos, abrange dois diferentes tipos de pesquisa: pesquisa bibliográfica e estudo de caso. Nesta primeira, buscou-se embasamento teórico suficiente para sustentar o trabalho em livros, artigos científicos, legislações e outras fontes que abordassem a temática da pesquisa. 0 estudo de caso caracterizou a parte prática da pesquisa, dedicando-se a entender, de forma aprofundada, como ocorrem alguns fenômenos cujas variáveis não se têm controle, neste caso, as variações linguísticas da Língua Brasileira de Sinais, Por fim, a partir dos resultados obtidos com o estudo de caso, deu-se 0 desenvolvimento da plataforma virtual Litoral Libras.

\subsection{Estudo de caso: coleta de dados}

Para o estudo de caso, o primeiro passo foi a coleta de dados, sendo que se definiu, primeiramente, estabelecer o perfil dos participantes. Assim, foram considerados critérios quanto às questões geográficas e mesmo nível de escolaridade, a fim de que os sujeitos analisados apresentassem um nível semelhante de proficiência da língua e de contemplar um público atuante com a Libras na região da pesquisa, sendo critérios de inclusão; ter ensino médio completo como formação mínima e habitar em uma das cidades do litoral norte gaúcho. Posteriormente à identificação, ocorreu o convite para os sujeitos participarem do estudo. Contataram-se indivíduos que já possuíssem um maior engajamento e participação dentro da comunidade surda local, pois teriam a língua em uso, a Libras, como forma de comunicação mais abrangente e integrante de sua identidade de surdo. A amostra contou com cinco (05) sujeitos provindos de cinco (05) diferentes municípios da região. As cidades escolhidas foram: Capão da Canoa, Imbé, Osório, Santo Antônio da Patrulha e Tramandaí.

Para a pesquisa, elegeram-se quatro listas semânticas contendo sinais em Libras de diferentes vocabulários. Esses vocabulários foram escolhidos pensando em quais sinais seriam os mais usuais na conversação e que iriam compor, futuramente, o glossário disponível na plataforma virtual Litoral Libras. Assim sendo, as respectivas listas foram pensadas para que cada sujeito investigado realizasse a sinalização de uma palavra por vez. Para tanto, o instrumento de coleta fez-se por meio de entrevista em Libras, a qual se deu através do registro das sinalizações por meio de filmagem, tendo em vista que 0 
objeto de pesquisa é uma língua gestual-visual. As imagens foram utilizadas exclusivamente no momento das análises pelas autoras. Todos concordaram e assinaram o Termo de Consentimento Livre e Esclarecido.

\subsection{Estudo de caso: análise de dados}

Após a coleta, iniciou-se o período de análise dos dados, no qual o principal objetivo foi verificar qual seria o sinal mais utilizado, pelos sujeitos pesquisados, para cada palavra, já que seria este o sinal utilizado na plataforma virtual Litoral Libras. Nesta etapa, realizou-se, primeiramente, a análise das variantes linguísticas, com foco na variação lexical e geográfica, identificadas na sinalização da comunidade surda do litoral norte gaúcho.

Para tanto, buscou-se perceber, em um primeiro momento, as variações de sinais existentes entre os próprios sujeitos da região, além de já verificar qual sinal para determinada palavra mais se repetiria. Após, foi feita uma comparação dos sinais usados pelos sujeitos locais em relação àqueles encontrados no Mini dicionário de Libras da Faders - Fundação de Articulação e Desenvolvimento de Políticas Públicas para Pessoas com Deficiência e com Altas Habilidades no Rio Grande do Sul (produzido na capital do estado do RS). E, por fim, fez-se essa mesma comparação utilizando o Dicionário llustrado Enciclopédico Trilíngue de Língua de Sinais Brasileira (contendo sinais de diferentes regiões do país) como guia comparativo. Assim, pôde-se ter um parâmetro de como os sujeitos surdos do litoral norte variam sua sinalização dentro da região em relação ao restante do estado e em relação a alguns territórios do país. A partir dessa análise comparativa, foi possível averiguar, de fato, se os dicionários disponíveis para consulta apresentavam sinais utilizados pelos habitantes da região em estudo ou se esses mostravam variantes linguísticas.

\subsection{Ciclo de desenvolvimento da plataforma virtual Litoral Libras}

Após a análise de dados - os quais demonstraram que, de fato, os sinais presentes em dicionários de outras localidades do país apresentavam sinais diferentes dos realizados na região identificou-se que não havia ferramentas virtuais, tais como plataformas virtuais, que possibilitassem aos surdos e ouvintes obterem sinais com as variantes linguísticas locais. Assim, surgiu, primeiramente, a ideia do desenvolvimento de um glossário de sinais, que, posteriormente, foi inserido em uma plataforma virtual: o site Litoral Libras. Assim, a plataforma busca oportunizar o acesso à aprendizagem de Libras 
para a comunidade local, a partir de sinais em uso do litoral norte gaúcho, mapeados com base no estudo de caso, o qual faz parte desta pesquisa.

Ressalta-se que, para a construção do site, contou-se com a colaboração de um estudante do curso superior de Análise e Desenvolvimento de Sistemas da instituição promovedora da pesquisa.

A escolha pelo desenvolvimento de um site deu-se devido a esse ser uma plataforma mais usual e conhecida da comunidade, apresentando maior usabilidade e acessibilidade. Além disso, esta plataforma oferecia os recursos pertinentes que eram necessários para o que se desejava desenvolver, como possibilidade da criação de diversas abas, ficheiros para armazenamento dos vídeos e textos, hiperlinks internos (CARVALHO; SIMÕES; SILVA, 2004).

Para a elaboração da plataforma virtual Litoral Libras, considerou-se o design pedagógico conforme Torrezzan (2014). Segundo a autora citada, o design pedagógico configura-se a uma concepção teórica que apoia a produção de materiais educacionais digitais somando-se ao planejamento técnico, gráfico e pedagógico. Assim, os fatores técnicos referem-se à programação do ambiente tecnológico e a ergonomia (facilidade de acesso e satisfação por parte dos usuários). Os fatores gráficos caracterizam-se pela estética e pelo design de interface, ou seja, tratam da imagem, mas não apenas no campo visual. Já, os fatores pedagógicos referem-se aos conteúdos e processos pedagógicos, tais como propostas de ações/atividades que possam desenvolver contextos de aprendizagem.

Neste sentido, em relação aos fatores técnicos, a plataforma foi desenvolvida a partir das linguagens de programação Java Script e PHP, se utilizando do framework Laravel. Para o banco de dados, utilizou-se MySQL. Quanto à ergonomia, o site aderiu um recurso de tradução para Libras de suas abas, isto é, ao lado de cada elemento, há um símbolo de acessibilidade que, quando clicado, abrese uma tela com a interpretação do que se encontra escrito em língua portuguesa. Ainda, cabe dizer que o site está hospedado no servidor do IFRS - Campus Osório, instituição que ampara a pesquisa.

O layout proposto no site consta com a seguinte divisão das seções, segundo essas abas: Glossário, Material Teórico, Quem Somos, Enviar Sugestões, Login. Dentro dessas abas, encontram-se os fatores pedagógicos que seriam os vídeos dos sinais em Libras para cada palavra analisada (Glossário), os textos informativos acerca da comunidade surda (Material Teórico) e o espaço para envio de sugestões de novos sinais pela comunidade (Enviar Sugestões). A aba Login pode ser acessada apenas pelas autoras para inserção de novos conteúdos.

Para a elaboração do design da interface e identidade visual, optou-se pela presença de tons azuis em alguns espaços (cor representativa para a comunidade surda) e a cor branca. Buscou-se evitar 
muitos elementos visuais que poluíssem as telas e atrapalhassem a visualização. Também se fez uso do contraste de fundo claro com letras escuras, bem como fonte ampliada.

A abordagem da plataforma virtual Litoral Libras segue o design pedagógico (TORREZZAN, 2014) e assim intenciona promover a aprendizagem democrática viabilizando a inclusão do público envolvido na investigação, ou seja, sujeitos surdos. Logo, o ambiente foi organizado a partir de itens de acessibilidade e foi projetado para ser uma plataforma virtual com vídeos explicativos em Libras, configurando uma característica bilíngue.

\section{Resultados e Discussão}

Os primeiros resultados desta pesquisa foram obtidos através do desenvolvimento da pesquisa bibliográfica e compuseram o referencial teórico deste estudo, Posteriormente, ocorreu a análise quanto às variantes linguísticas dos usuários de Libras do litoral norte gaúcho, que serviu como base para 0 desenvolvimento da plataforma virtual, demonstrando a necessidade de recursos tecnológicos para região, com o objetivo de auxiliar na pesquisa e no aprendizado de sinais em Libras.

\subsection{Dados obtidos a partir da análise das variantes linguísticas com foco no léxico e fator geográfico}

Nesta etapa, o método utilizado para efetuar as análises foi o da contagem de vezes em que cada sujeito variou a sinalização em relação aos dois dicionários e em relação aos sujeitos das demais cidades. Sobre este último, veja o exemplo abaixo para a palavra "colchão", cujos sinais correspondentes, encontrados nos dicionários, já foram apresentados na introdução deste artigo:

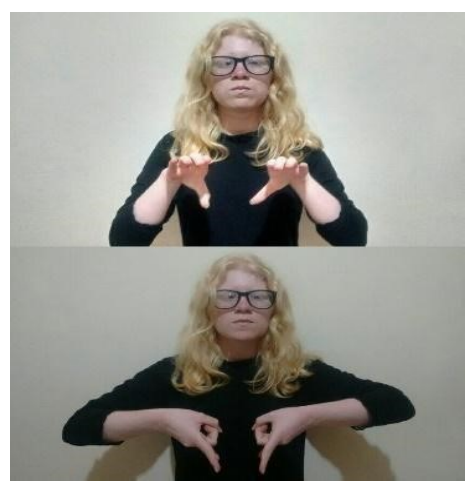

Figura 3. Sinal de colchão realizado em Imbé, Osório e Santo Antônio da Patrulha Fonte: Elaborada pelas autoras. 


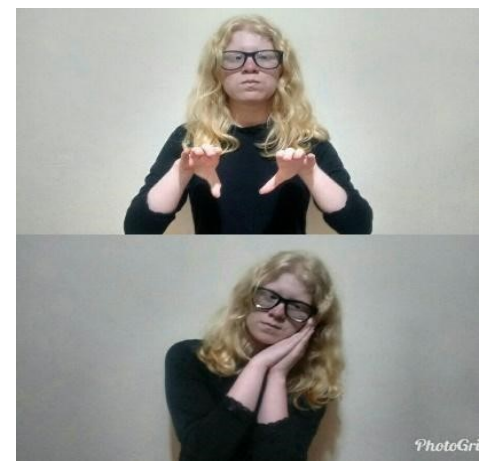

Figura 5. Sinal de colchão realizado em Tramandaí Fonte: Elaborada pelas autoras.

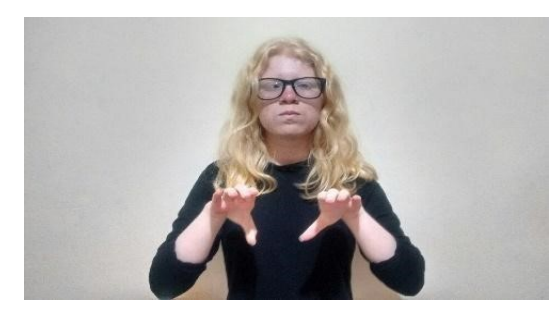

Figura 4. Sinal de colchão realizado em Capão da Canoa Fonte: Elaborada pelas autoras.

Neste caso, os sujeitos de Imbé, Osório, Santo Antônio da Patrulha e Tramandaí variam a sinalização em apenas 2 vezes, enquanto o sujeito de Capão da Canoa varia em 4 vezes. Este processo foi realizado com todos os sinais das quatro listas. Após efetuar-se a contabilização de todas as variações, foram construídos gráficos para demonstrar, de forma mais clara, como elas ocorrem. Isto foi feito em cada uma das listas, por cada sujeito, nas três etapas da análise. Veja abaixo os gráficos.

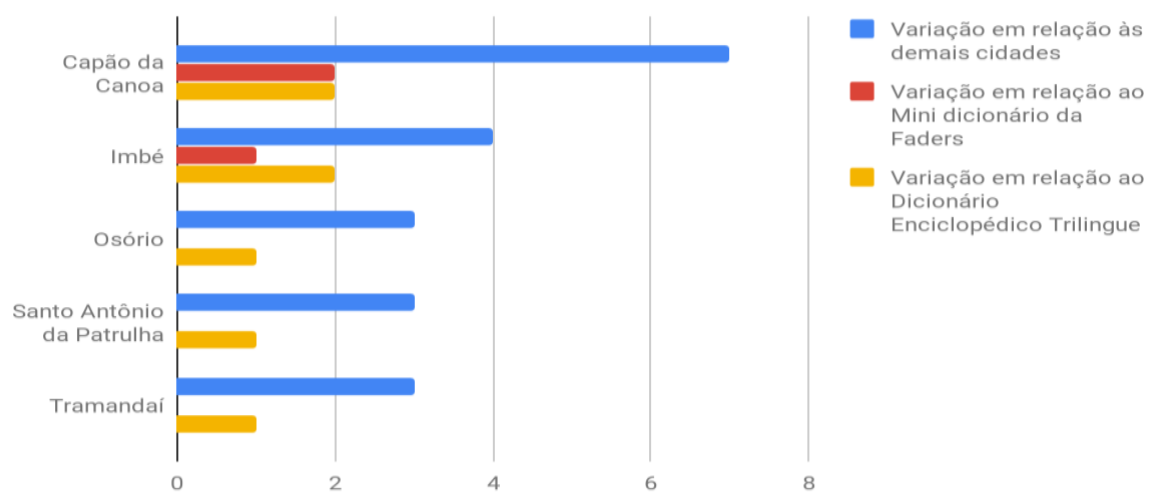

Gráfico 1. Variações linguísticas registradas na lista de "adjetivos" Fonte: Elaborado pelas autoras. 


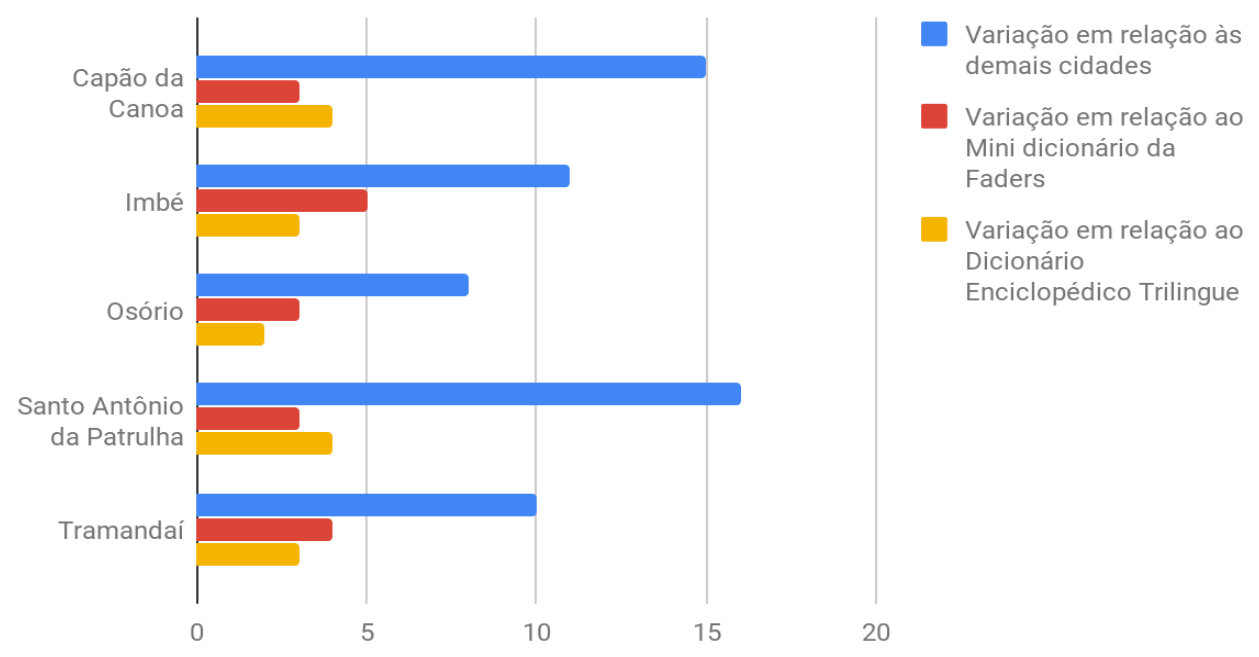

Gráfico 2. Variações linguísticas registradas na lista de "objetos" Fonte: Elaborado pelas autoras.

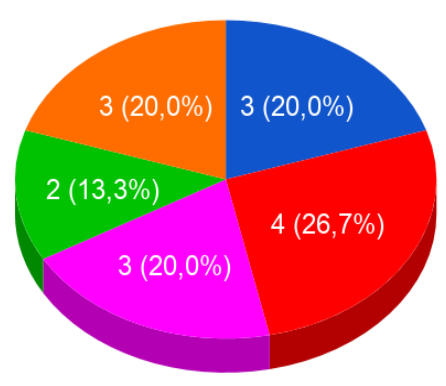

Capão da Canoa

- Imbé

Osório

Santo Antônio da Patrulha

- Tramandaí

Gráfico 3. Variações linguísticas registradas na lista de "nomes das cidades do litoral norte gaúcho" Fonte: Elaborado pelas autoras.

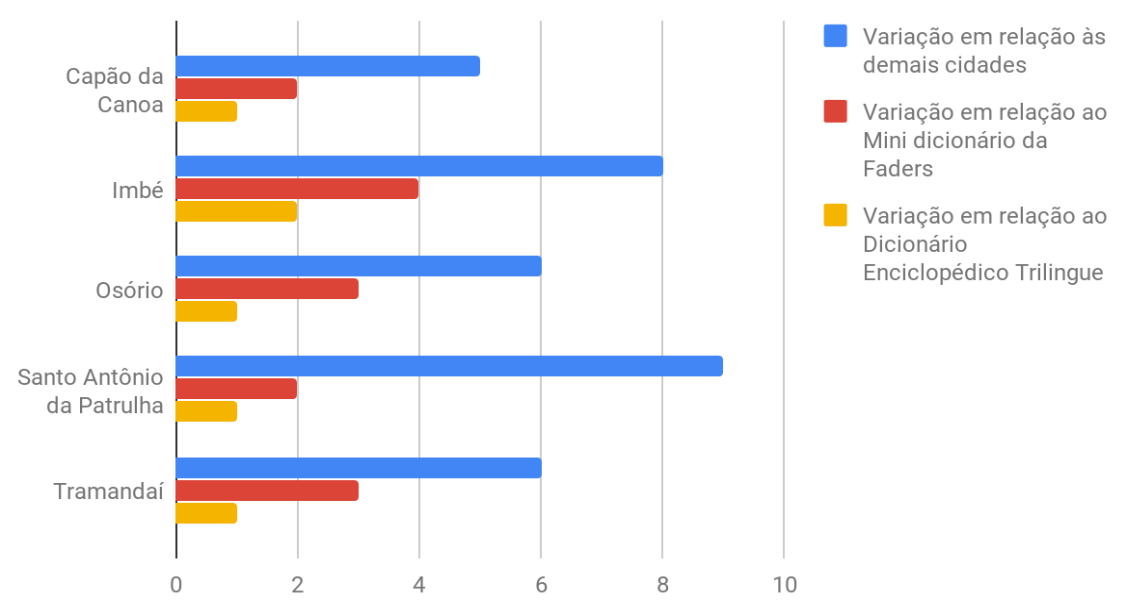

Gráfico 4. Variações linguísticas registradas na lista de "verbos" Fonte: Elaborado pelas autoras.

LínguaTec, Instituto Federal de Educação, Ciência e Tecnologia do Rio Grande do Sul, Bento Gonçalves 
Tendo em vista os resultados obtidos, pode-se dizer que as variações linguísticas ocorrem tanto entre os surdos do litoral norte gaúcho quanto em relação aos dicionários analisados. Essas diferenciações ocorrem nos parâmetros primários da Libras: movimento, configuração de mãos ou localização de mãos. Por ser uma língua gestual, as variações são bastante acentuadas, o que demonstra a crescente necessidade de haver uma plataforma virtual de estudos particularmente voltada a uma região específica.

Foi possível constatar que a lista em que mais houve variação, tanto em relação à sinalização dentro da própria região quanto em relação aos dois dicionários, foi a lista de objetos. Isso pode ser explicado, por um lado, pelo fato de as palavras das listas terem sido apresentadas de forma isolada, sem estarem contextualizadas em uma frase ou texto, o que abriu precedentes para interpretações subjetivas, ainda mais considerando-se que os objetos têm diferentes finalidades. A palavra cartão, por exemplo, pode ser cartão de crédito, cartão de banco, cartão de presente, etc. Já as listas em que menos houve variação foram a de adjetivos e a de verbos.

Como já foi dito, para concluir que existem variações nos sinais, foram levados em consideração os parâmetros primários da Libras. No entanto, perceberam-se, ainda, diferenças marcantes na intensidade com que cada um dos pesquisados realizou o sinal. O sinal da palavra convidar, por exemplo: todos realizaram da mesma forma, mas colocando mais ou menos intensidade e ênfase no movimento. Ainda, houve diferenças quanto à expressão facial (componente não manual, muito importante das línguas de sinais). Isto é análogo à entonação utilizada nas línguas orais, em que cada um tem seu jeito próprio de expressar uma mesma palavra, os considerados idioletos.

\subsection{Plataforma virtual de aprendizagem: Litoral Libras}

Após os resultados obtidos com o estudo de caso, foi desenvolvida a plataforma Litoral Libras, descrita metodologicamente na seção anterior. Esta, por sua vez, já se encontra disponível (veja Figura 6 e 7) e pode ser acessada, a partir de qualquer dispositivo, pelo link: litorallibras.osorio.ifrs.edu.br. 


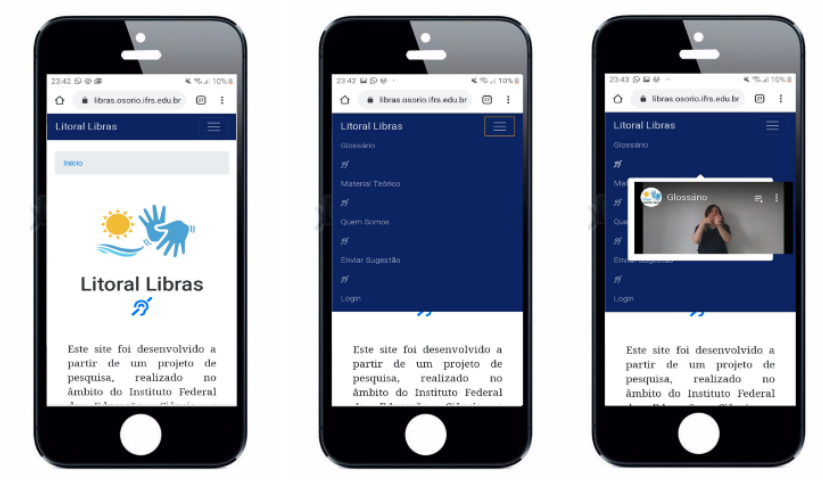

Figura 6. Interfaces da plataforma "Litoral Libras"

Fonte: Elaborada pelas autoras.
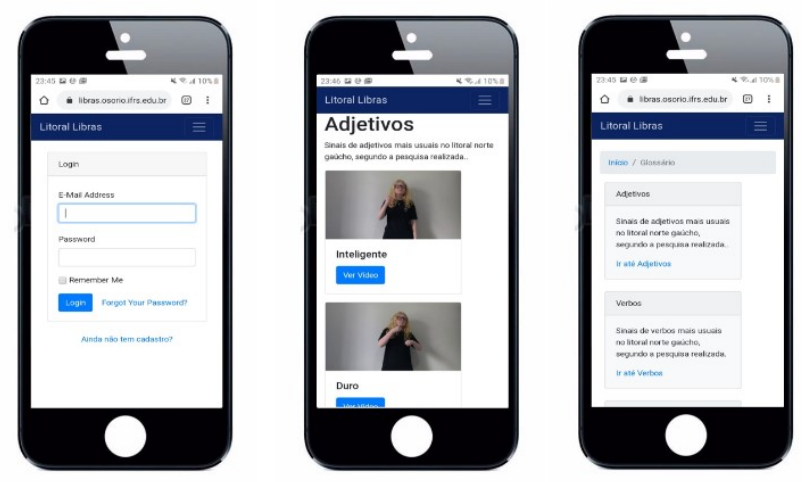

Figura 7. Interfaces da plataforma "Litoral Libras" Fonte: Elaborada pelas autoras.

A plataforma está associada ao site oficial do IFRS-Campus Osório e apresenta o mesmo domínio, podendo ser localizada facilmente pelos interessados, Além disso, houve sua divulgação nas redes sociais do Campus e também envio do link para os sujeitos que colaboraram com o estudo. $O$ site é bastante divulgado também nos projetos de ensino e extensão realizados na instituição para ensino de Libras, sendo utilizado como recurso pedagógico para essas ações.

Atualmente, estão disponíveis no glossário aproximadamente 35 sinais distribuídos entre os vocabulários de adjetivos, nomes das cidades do litoral norte gaúcho, objetos e verbos. Ressalta-se que há a pretensão da ampliação do número de sinais disponíveis, inclusive a partir das contribuições dadas pela comunidade na aba Enviar Sugestões.

\subsection{Uma alternativa para o aprendizado de Libras em tempos de pandemia}

Tendo em vista a atual pandemia do Novo Coronavírus (COVID-19) e o consequente isolamento social na quase totalidade dos países do mundo, "o sistema educacional, assim como todas as áreas da 
sociedade, busca alternativas para se adaptar a nova realidade com alternativas que possam atender a demanda dos envolvidos." (MARQUES, 2020, p. 32).

Há, nesse contexto, a ascensão do uso das tecnologias aplicadas à educação que emergem como uma excelente alternativa para que os processos de ensino e aprendizagem, bem como as relações pedagógicas, não sejam interrompidos indeterminadamente. Neste sentido, a plataforma de aprendizagem "Litoral Libras" mostra-se como uma ferramenta adequada e qualificada à aprendizagem de Libras no contexto do isolamento social destinada à comunidade do litoral norte gaúcho. Neste momento em que muitas pessoas acabam por ter de permanecer em suas residências por um longo período, abre-se espaço para novas oportunidades de aprendizagem, como o da Língua Brasileira de Sinais.

Além disso, segundo Pedrosa (2020), a tecnologia aplicada à educação não deve ser encarada apenas como uma ferramenta auxiliar neste processo, mas, sim, como um instrumento efetivo de intervenção na construção de uma sociedade igualitariamente democrática, crítica e inclusiva.

\section{Considerações Finais}

Ao fim deste estudo, é possível concluir que diversas palavras dos vocabulários delimitados apresentam variações linguísticas lexicais, como pôde ser visto na subseção Estudo de caso: análise de dados, e tendo como base o critério geográfico, em que as análises se deram a partir do território do litoral norte gaúcho. Essas variações mostraram-se bastante acentuadas em relação aos sinais encontrados nos dois dicionários adotados e, a partir disso, reafirmou-se a necessidade da construção de um glossário regional.

Compreende-se que é imprescindível que existam mecanismos que auxiliem na difusão e nos processos de ensino e aprendizagem da Libras, uma vez que esta é a segunda língua oficial do Brasil. No entanto, é necessário que estes mecanismos sejam coerentes com a região em que será implantada para que 0 aprendizado seja efetivo. Desta maneira, faz-se notória a relevância da plataforma virtual "Litoral Libras", produzida a partir deste estudo, para a comunidade local. Os indivíduos interessados no aprendizado da Libras passarão a ter amparo neste processo, possuindo à sua disposição uma plataforma com sinais locais, o que antes era inexistente. Além de valorizar a cultura regional da comunidade surda presente, também, na língua. 
Tendo em vista que a Libras organiza a identidade de seus usuários, é necessário que haja um amparo a estes indivíduos surdos e deficientes auditivos na aquisição e/ou aprendizado da língua. $E$ isto deve ser feito respeitando as características e subjetividades do local em que estão inseridos.

Ademais, considerando o que foi visto, de que o espaço virtual se coloca como um novo ambiente para desenvolvimento dos processos de ensino e aprendizagem e, ainda, que os sujeitos surdos passaram a estar atuantes nas redes sociais e nos meios digitais, demonstra-se que as novas tecnologias sociais destinadas a esse público receberão maior adesão quando inseridas neste novo espaço de ação e atuação da comunidade surda.

Logo, desenvolver uma pesquisa que divulgue e amplie as possibilidades de aprendizado da língua de sinais, além de amparar o processo de inclusão social, é fundamental e, certamente, causará importantes impactos em nossa comunidade local. A forma mais efetiva de incluir os sujeitos surdos em nossa sociedade é quebrando as barreiras de comunicação e garantindo a acessibilidade comunicativa entre eles e ouvintes. Poderemos, assim, construir uma sociedade em que todos tenham vez, voz e visibilidade, independentemente de suas necessidades específicas.

\section{Referências}

BAGNO, M. Preconceito Linguístico: o que é como se faz. 49. ed. São Paulo, SP: Loyola, 2007.

BISOL, C.; SPERB, T. T. Discursos sobre a surdez: Deficiência, Diferença, Singularidade e Construção de Sentido. Psicologia: Teoria e Pesquisa. Brasília, V. 27, n. 1, p. 7-13, 2010. Acesso em: 01 jul. 2020. https://doi.org/10.1590/S0102-37722010000100002

BRASIL. Lei $n^{\circ}$. 10.436, DE 24 DE ABRIL DE 2002. Dispõe sobre a Língua Brasileira de Sinais - Libras e dá outras providências. Diário Oficial da União, DF, 25 abr.2002. Disponível em: https://presrepublica.jusbrasil.com.br. Acesso em: 20 jul. 2020.

BRASIL. Lei $n^{\circ}$ 13.146, DE 6 DE JULHO DE 2015. Institui a Lei Brasileira de Inclusão da Pessoa com Deficiência (Estatuto da Pessoa com Deficiência). Diário Oficial da União, Brasília, DF, 7 jul. 2915. Disponível em: http://www4.planalto.gov.br/legislacao/portal-legis/legislacao-1/leis-ordinarias Acesso em: 17 jan. 2019.

BRASIL. Decreto $n^{\circ}$ 5.626, 22 de dezembro de 2005. Regulamenta a Lei no 10.436, de 24 de abril de 2002, que dispõe sobre a Língua Brasileira de Sinais - Libras. Disponível em: http://www.planalto.gov.br/ccivil_03/_ato2004-2006/2005/decreto/d5626.htm. Acesso em: 20 jul.2020.

CASTRO, G. J. Variação Linguística em língua de sinais brasileira - foco no léxico. 2011. 123 f. Dissertação (Mestrado) - Curso de Linguística, Universidade de Brasília, Brasília, 2011.

CAPOVILLA, F.C.; RAPHAEL, W.D. Dicionário Enciclopédico Ilustrado Trilíngue da Língua de Sinais Brasileira. 3.ed. São Paulo, SP: Editora da Universidade de São Paulo, 2008. 
CARVALHO, A.A.A.; SIMÕES, A.; SILVA, J.P. Indicadores de Qualidade e de Confiança de um Site. In: ALVES, M. P.; MACHADO, E.A. Atas da II Jornada da Secção Portuguesa da ADMEE: A avaliação e a validação das competências em contextos escolares e profissionais. Braga, Portugal: CIED, IEP, 2004.

COMASSETO, L.S. Novos espaços virtuais para o ensino e a aprendizagem a distância: estudo da aplicabilidade dos desenhos pedagógicos. (Tese). Florianópolis: Centro Tecnológico, Universidade Federal de Santa Catarina, 2006.

COELHO, I. L.; GORSKI, E. M.; SOUZA, C. M. N.; MAY, G. H. Para Conhecer Sociolinguística. São Paulo, SP: Contexto, 2015.

COSTA, V. L. A. A importância do conhecimento da variação linguística. Educar. n.12. Curitiba: Editora da UFPR, 1996, p.51-60. Acesso em: 22 jul. 2020. https://doi.org/10.1590/0104-4060.157

GABARDO, P.; QUEVEDO, S.R.P.; ULBRICHT, V; R. Estudo Comparativo das Plataformas de ensinoaprendizagem. Enc. Bibli: R. Eletr. Bibliotecon. Ci, Inf., Florianópolis, n. esp., $2^{0}$ sem., p. 65-84. https://doi.org/10.5007/1518-2924.2010v15nesp2p65

GESSER, A. LIBRAS? Que língua é essa?: crenças e preconceitos em torno da língua de sinais e da realidade surda. 1. ed. São Paulo: Parábola Editorial, 2009.

HUNT, T; CALLARI, A. O poder das redes sociais. São Paulo: Editora Gente, 2010

KARNOPP, L. Fonética e Fonologia. Ensino a Distância, Curso de Graduação em Letras Libras, Universidade Federal de Santa Catarina (UFSC), 2009.

LANE, H. L. Do Deaf People Have a Disability? Gallaudet University Press. v. 2, n. 4, p. 356-379, 2002. https://doi.org/10.1353/sls.2002.0019

MACHADO, Aline Dubal. As interações do sujeito com surdez severa e o processo de construção de identidade. Santa Maria: UFSM - Programa de Pós-Graduação em Educação Especial, 2002.

MARQUES, R. A ressignificação da educação e o processo de ensino e aprendizagem no contexto da pandemia da COVID 19. Boletim de Conjuntura (BOCA). v. 3, n. 7, 2020.

MONTEIRO, R.; SILVA, D.N.H; RATNER, C. Surdez e Diagnóstico: narrativa de surdos adultos. Psicologia: teoria e pesquisa. Brasília, v. 32, $p$ 1-7. 2013. Disponível em: http://www.scielo.br/pdf/ptp/v32nspe/1806-3446-ptp-32-spe-e32ne210.pdf Acesso em: 02 ago. 2020.

PEDROSA, G. F. S. O uso de tecnologias na prática docente em um pré-vestibular durante a pandemia da COVID-19. Boletim de Conjuntura (BOCA), v. 2, n. 6, 2020.

QUADROS, R.M.; KARNOPP, L.B. Língua de sinais brasileira: estudos linguísticos. Porto Alegre: Artmed, 2004. https://doi.org/10.18309/anp.v1i16.560

QUADROS, R.M. Língua de Herança: língua brasileira de sinais. Porto Alegre, RS: Penso, 2017.

RIO GRANDE DO SUL. FADERS, Minidicionário. Porto Alegre: Serviço de Ajudas Técnicas, 2010.

SÁ, N. R. L. de. Cultura, poder e educação de surdos. São Paulo, SP: Paulinas, 2006. 
SANTANA, A. P.; BERGAMO, A. Cultura e identidade surdas: Encruzilhada de lutas sociais e teóricas. Educação e Sociedade. Campinas, v. 26, n. 91, p. 565-582, 2005. Acesso em: 25 jul. 2020. https://doi.org/10.1590/S0101-73302005000200013

SANTOS, I. P. Linguística: Estudos avançados. São Paulo, v. 8, n. 22, p. 481-486, 1994. Acesso em: 05 ago. 2020. https://doi.org/10.1590/S0103-40141994000300069

SANTOS, A. N.; PEREIRA, K. A.; LEBEDEFF, T. B. Novas tecnologias e suas contribuições para o registro e a divulgação das línguas de sinais: uma discussão sobre o projeto SpreadTheSign no Brasil. In: CORREAA, Y.; CRUZ, C.R. (Orgs.). Língua Brasileira de Sinais e Tecnologias Digitais. Porto Alegre: Penso, 2019.

STROBEL, K. As imagens do outro sobre a cultura surda. Florianópolis, SC: Ed. da UFSC, 2008.

TORREZZAN, C. A. W. CONSTRUMED: Metodologia para a Construção de Materiais Educacionais Digitais Baseados no Design Pedagógico. 2014. Tese (Doutorado em Informática na Educação), Programa de Pós-Graduação em Informática na Educação, Universidade Federal do Rio Grande do Sul (UFRGS), Porto Alegre, 2014.

Data de submissão: 20/09/2020. Data de aprovação: 23/10/2020. 